\title{
TINJAUAN PENGELOLAAN KEUANGAN DESA DAN IMPLIKASINYA TERHADAP AKUNTABILITAS
}

\author{
Duwi Agustina \\ Fakultas Ekonomi Universitas Bangka Belitung \\ Email: ag.omikadewi@gmail.com
}

\begin{abstract}
Village Financial Management and It's Implication Towards Accountability. The purpose of this study was to examine empirically the effect of Village Apparatus capacity, organizational commitment, implementation of Village Financial System (SISKEUDES) and supervision of Badan Permusyawaratan Desa toward the village financial management. This study also aims to determine the effect of village financial management on the accountability in Banyu Asin Village, Riau Silip Sub-district, Bangka Regency. The data used in this study are primary data obtained directly by distributing questionnaires to village officer involved in village financial management, consisted of Village Government, Badan Usaha Milik Desa (BUMdesa) and Lembaga Pemberdayaan Masyarakat (LPM). The sample of research were taken by saturation sampling method (census) amounts 50 respondents The statistical analysis uses SmartPLS 3.2.8 program with PLS-PM (Path Modelling) structural equation model. The result of this research showed that the capacity of village apparatus has a positive and not significant effect on village financial management, organizational commitment has a positive and significant effect on village financial management., implementation of village financial system (SISKEUDES) has a positive and significant effect on village financial management, and supervision of Badan Permusyawaratan Desa has a positive and significant effect on village financial management. Other than that, village financial management has a positive and significant effect toward accountability
\end{abstract}

Keywords: Accountability, Capacity of Apparatus, Organizational Comitment, Village Financial Management

\section{PENDAHULUAN}

Desa saat ini ditempatkan sebagai ujung tombak pelaksanaan pembangunan dan peningkatan kesejahteraan masyarakat. Terlebih, pemerintah kian memprioritaskan kemajuan ekonomi desa demi mendorong terciptanya kemakmuran yang bersifat adil dan merata. Kesungguhan pemerintah dibuktikan dengan disahkannya Undang-Undang Nomor 6 Tahun 2014 tentang Desa yang membawa perubahan cukup signifikan bagi tata kelola pemerintahan desa. Ditetapkannya Undang-Undang tersebut secara regulasi membuat desa tidak lagi menjadi bagian dalam Undang-Undang Nomor 32 Tahun 2004 tentang Pemerintahan Daerah. Selain itu, usaha lain yang dilakukan pemerintah adalah dengan membentuk Agenda Pembangunan Nasional yang tertuang dalam Peraturan Presiden Nomor 2 Tahun 2015 tentang Rencana Pembangunan Jangka Menengah Nasional yang berkomitmen dalam membangun Indonesia dari pinggiran, dengan salah satu fokus utamanya adalah mengusahakan percepatan pembangunan desa. 
Akuntabilitas atau pertanggungjawaban merupakan suatu bentuk keharusan seseorang (pimpinan/pejabat/pelaksana) untuk menjamin bahwa tugas dan kewajiban yang diembannya sudah dilaksanakan sesuai ketentuan yang berlaku. Akuntabilitas dalam Pemerintah Desa melibatkan kemampuan Pemerintah Desa untuk mempertanggungjawabkan kegiatan yang dilakukan dalam kaitannya dengan pembangunan dan pengelolaan kepentingan desa, serta penting untuk menjamin terlaksananya nilai-nilai seperti efisiensi, efektivitas, reliabilitas dan prediktibilitas. Akuntabilitas pada hakikatnya tidak abstrak, tapi konkrit dan harus ditentukan oleh hukum melalui seperangkat prosedur mengenai hal apa yang harus dipertanggungjawabkan (Nafidah dan Anisa, 2017).

Kapabilitas Aparatur Desa bukan satu-satunya faktor yang dipertimbangkan dapat mempengaruhi prinsip akuntabilitas, ada beberapa faktor yang berkaitan langsung dengan aparatur yang melakukan pengelolaan keuangan, namun ada juga yang dipengaruhi oleh lingkungan organisasi itu sendiri. Komitmen organisasi sebagai penggambaran tingkat kepercayaan pegawai terhadap organisasi dikatakan menjadi faktor yang ikut mempengaruhi tinggi rendahnya komitmen karyawan terhadap organisasi akan menentukan kinerja yang akan dicapai oleh organisasi tersebut.

Faktor lainnya yang berpengaruh terhadap pengelolaan keuangan desa yaitu implementasi aplikasi tata kelola keuangan desa atau yang disebut Sistem Keuangan Desa (SISKEUDES). Sistem aplikasi yang secara perdana diluncurkan bulan Juni tahun 2015 lalu sejatinya bertujuan untuk mempercepat peningkatan akuntabilitas dan transparansi pengelolaan keuangan desa. Implementasi Sistem Keuangan Desa (SISKEUDES) diharapkan dapat mempermudah Aparatur Desa dalam proses pertanggung jawaban serta mampu meningkatkan kualitas laporan keuangan yang tepat waktu dan akuntabel. Oleh karena itu, pemanfaatan teknologi berupa aplikasi SISKEUDES dirasakan akan berdampak pada pengelolaan dan pelaporan keuangan desa.

Salah satu hal yang tidak kalah penting dalam menggiring akuntabilitas pengelolaan keuangan desa yaitu adanya kontrol atau pengawasan. Kontrol dari masyarakat dalam mengawasi penggunaan dana desa maupun dana lainnya sangat penting agar dana dipergunakan sesuai dengan peruntukkannya. Permedagri Nomor 113 Tahun 2014 menyatakan bahwa Badan Permusyawaratan Desa (BPD) adalah institusi yang bertanggungjawab menjalankan fungsi pemerintahan yang anggotanya merupakan representasi penduduk desa berdasarkan keterwakilan area yang ditetapkan secara demokratis. Badan Permusyawaratan Desa (BPD) merupakan aktor masyarakat politik di tingkat desa yang memainkan peran sebagai jembatan antara elemen masyarakat dan Pemerintah Desa, sehingga BPD dapat menjadi faktor lain yang mempengaruhi proses pengelolaan keuangan desa.

Berkedudukan di Kecamatan Riau Silip, Kabupaten Bangka, Desa Banyu Asin memiliki wilayah seluas 3.498,00 Ha dan jumlah penduduk sebanyak 1.596 jiwa (Profil Desa Banyu Asin, 2018). Dalam proses pengelolaan keuangan, Desa Banyu Asin sering kali mengalami beberapa kendala dalam mengoptimalkan penggunaan dana yang dimiliki sehingga menarik untuk diteliti. Kendala tersebut seperti pembangunan desa yang kurang memberikan manfaat optimal bagi masyarakat dan kendala-kendala lainnya. Beberapa hal yang mungkin saja menyebabkan kurang optimalnya pengelolaan keuangan desa seperti rendahnya kapabilitas Aparatur Desa, masih minimnya pengawasan dari BPD, kurangnya komitmen organisasi atau dari sisi implementasi aplikasi SISKEUDES yang belum optimal.

Berdasarkan uraian latar belakang di atas, maka penulis ingin meneliti tentang Kapabilitas Aparatur Desa, Komitmen Organisasi, Implementasi SISKEUDES, Pengawasan BPD berpengaruh terhadap pengelolaan keuangan desa dan Pengelolaan Keuangan Desa berpengaruh terhadap akuntabilitas. 


\section{KAJIAN LITERATUR}

\section{Desa dan Pemerintahan Desa}

Berdasarkan Undang-Undang Nomor 6 Tahun 2014 Pasal 1 tentang Desa disebutkan bahwa Desa adalah desa dan desa adat atau yang disebut dengan nama lain, selanjutnya disebut Desa, adalah kesatuan masyarakat hukum yang memiliki batas wilayah yang berwenang untuk mengatur dan mengurus urusan pemerintahan, kepentingan masyarakat setempat berdasarkan prakarsa masyarakat, hak asal usul, dan/ atau hak tradisional yang diakui dan dihormati dalam sistem pemerintahan Negara Kesatuan Republik Indonesia.

\section{Keuangan Desa}

Keuangan desa didefinisikan sebagai semua hak dan kewajiban desa yang dapat dinilai dengan uang, serta segala sesuatu baik berupa uang maupun berupa barang yang dapat dijadikan milik desa sehubungan dengan pelaksanaan hak dan kewajiban tersebut.

Laporan keuangan desa berdasarkan Peraturan Menteri dalam Negeri (Permendagri) Nomor 113 Tahun 2014 yang harus dilaporkan pemerintah desa, antara lain : Anggaran; Buku kas; Buku pajak; Buku bank; dan Laporan Realisasi Anggaran (LRA).

\section{Pengelolaan Keuangan Desa}

Menurut Peraturan Menteri Dalam Negeri Nomor 113 Tahun 2014, pengeolaan keuangan desa adalah keseluruhan kegiatan yang meliputi perencanaan, pelaksanaan, penatausahaan, pelaporan dan pertanggungjawaban keuangan desa. Kekuasaan pengelolaan keuangan desa dipegang oleh Kepala Desa, namun dalam pelaksanaannya, kekuasaan tersebut sebagian dikuasakan kepada Perangkat Desa sehingga pelaksanaan pengelolaan keuangan dilaksanakan secara bersama-sama oleh Kepala Desa dan Pelaksana Teknis Pengelolaan Keuangan Desa (PTPKD

\section{Kapabilitas Aparatur Desa}

Kapabilitas didefinisikan sebagai kemampuan atau kompetensi yang memungkinkan setiap individu, organisasi, jaringan kerja/sektor, dan sistem yang lebih luas dalam melaksanakan fungsi-fungsinya. Pemaknaan kapabilitas tidak sebatas memiliki keterampilan (skill) namun lebih dari itu, yaitu lebih paham secara mendetail sehingga benar benar menguasai kemampuan dari titik kelemahan hingga cara mengatasinya

\section{Implementasi Sistem Keuangan Desa (SISKEUDES)}

Permendagri Nomor 113 Tahun 2014 tentang Pengelolaan Keuangan Desa mangamanatkan pengelolaan keuangan desa yang transparan, akuntabel dan partisipatif, sehingga ide tentang aplikasi SISKEUDES dicetuskan. Pemanfaatan teknologi dalam bentuk penerapan aplikasi SISKEUDES dalam pengelolaan keuangan desa diharapkan mampu membantu Pemerintah Desa dalam proses pelaporan keuangan desa serta dapat mengoptimalkan akuntabilitas pengelolaan keuangan desa.

\section{Pengawasan Badan Permusyawaratan Desa (BPD)}

Pengawasan secara umum dapat didefinisikan sebagai cara suatu organisasi dalam mewujudkan kinerja dengan berlandaskan pada prinsip efisiensi dan efektivitas demi mendukung terwujudnya visi dan misi organisasi yang telah ditetapkan sebelumnya. Dalam Bahasa Inggris, istilah pengawasan disebut controlling, yang oleh Terry (dalam Fahmi, 2016) dikatakan bahwa: Keseluruhan pengawasan tidak hanya bertujuan untuk mengawasi dan mengamati, fungsi pengawasan lebih jauh adalah untuk menghindari terjadinya penyimpangan-penyimpangan yang mungkin terjadi dengan segeramengambil tindakan korektif sehingga dapat memastikan tercapainya tujuan dari pelaksanaan suatu tindakan atau kegiatan yang telah direncanakan sebelumnya. 


\section{Konsep Akuntabilitas}

Fenomena yang terjadi dalam perkembangan sektor publik saat ini adalah semakin meningkatnya tuntutan pelaksanaan akuntabilitas bagi organisasi-organisasi sektor publik. Tidak hanya bagi Pemerintahan Pusat dan Pemerintah Daerah, tuntutan untuk terealisasinya akuntabilitas juga berlaku bagi Pemerintahan Desa. Akuntabilitas dirasakan penting agar pemberian informasi dan hak-hak publik dapat tercapai.

Prinsip-prinsip akuntabilitas yang perlu diperhatikan dalam pelaksanaan akuntabilitas dilingkungan pemerintah menurut Nafidah dan Anisa (2017) adalah :

1. Harus ada komitmen dari pimpinan dan seluruh staf instansi untuk melakukan pengelolaan pelaksanaan misi agar akuntabel;

2. Harus merupakan suatu sistem yang dapat menjamin penggunaan sumber daya secara konsisten dengan peraturan perundang-undangan yang berlaku;

3. Harus dapat menunjukkan tingkat pencapaian tujuan dan sasaran yang telah ditetapkan;

4. Harus berorientasi pada pencapaian visi dan misi serta hasil dan manfaat yang diperoleh;

5. Harus jujur, objektif, transparan, dan inovatif sebagai katalisator perubahan manajemen instansi pemerintah dalam bentuk pemutakhiran metode teknik pengukuran kinerja dan penyusunan laporan akuntabilitas.

\section{Hipotesis}

$\mathrm{Ha}_{1} \quad$ : Kapabilitas Aparatur Desa berpengaruh positif terhadap pengelolaan keuangan desa

$\mathrm{Ha}_{2}$ : Komitmen organisasi berpengaruh positif terhadap pengelolaan keuangan desa.

$\mathrm{Ha}_{3}$ : Implementasi SISKEUDES berpengaruh positif terhadap pengelolaan keuangan desa.

$\mathrm{Ha}_{4}$ : Pengawasan BPD berpengaruh positif terhadap pengelolaan keuangan desa.

$\mathrm{Ha}_{5} \quad$ : Pengelolaan keuangan desa berpengaruh positif terhadap akuntabilitas

\section{METODE}

\section{Populasi dan Sampel}

Populasi dalam penelitian ini adalah seluruh Aparatur Desa di Kecamatan Riau Silip Kabupaten Bangka. Dalam penelitian ini, teknik yang digunakan adalah nonprobability sampling. Dengan cara ini maka tidak semua unsur populasi diberikan peluang atau kesempatan yang sama untuk dipilih menjadi anggota sampel. Jenis teknik nonprobability sampling yang dipilih dalam menentukan jumlah sampel adalah sampling jenuh atau sensus. Sampel dalam penelitian ini yang terdiri dari Kepala Desa, Sekretaris Desa, Pelaksana Teknis (Kasi Pemerintahan, Kasi Pembangunan, Kasi Kesejahteraan Rakyat, Kaur Keuangan) dan Pelaksana Kewilayahan (Kepala Dusun) yang berjumlah 50 orang.

\section{Teknik Analisis Data}

Setelah data terkumpul dan dirasakan cocok dengan penelitian, maka peneliti melakukan analisis data melalui alat uji statistik dengan menggunakan alat olah data berupa SmartPLSversi 3.2.8.

\section{Evaluasi Model Pengukuran (Outer Model)}

Model pengukuran atau outer model dilakukan untuk menilai validitas dan reabilitas konstruk. Uji yang dilakukan meliputi : Convergent Validity, Discriminant Validity, Reliability, 


\section{Evaluasi Model Struktural (Inner Model)}

Uji yang dilakukan meliputi : $R$-Square, Effect Size $\left(f^{2}\right)$, Predictive Relevance $\left(Q^{2}\right.$ Value).

\section{Pengujian Hipotesis}

Uji yang dilakukan meliputi : Uji Signifikansi Parameter Individual (Uji Statistik t) dan Uji Signifikansi Simultan (Uji Statistik F).

\section{HASIL DAN PEMBAHASAN}

\section{Evaluasi Model Pengukuran / Outer Model}

\section{Uji Convergent Validity}

Tahapan pertama dalam mengevaluasi validitas konstruk adalah dengan menampilkan nilai loading factor setiap indikator secara menyeluruh. Adapun gambaran nilai loading factor dan model pengukuran adalah sebagai berikut :

\section{Tabel IV.17}

\section{Nilai Loading Factor Variabel}

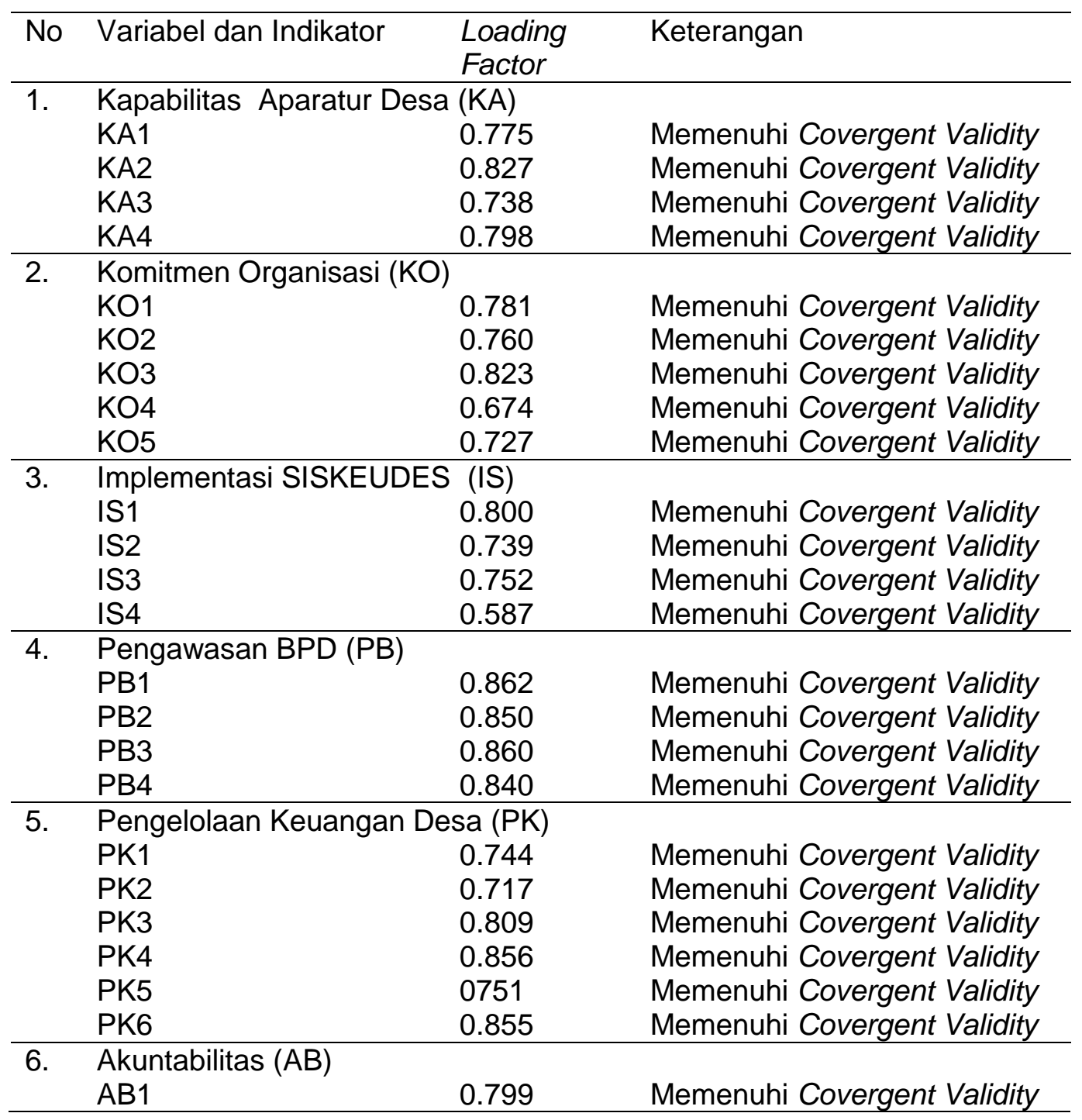




\begin{tabular}{lll}
\hline AB2 & 0.851 & Memenuhi Covergent Validity \\
AB3 & 0.876 & Memenuhi Covergent Validity \\
AB4 & 0.669 & Memenuhi Covergent Validity \\
\hline
\end{tabular}

Sumber: Data diolah dengan SmartPLS 3.2.8, 2019

Tabel IV.18

Nilai Akar AVE Hasil Uji Discriminant Validity

\begin{tabular}{llccccc}
\hline \multicolumn{1}{c}{ Variabel } & AB & IS & KA & KO & PB & PK \\
\hline $\begin{array}{l}\text { Akuntabilitas } \\
\text { Implementasi }\end{array}$ & $\mathbf{0 . 8 0 3}$ &. & & & & \\
$\begin{array}{l}\text { SISKEUDES } \\
\text { Kapabilitas Aparatur }\end{array}$ & 0.691 & $\mathbf{0 . 7 2 4}$ & & & & \\
$\begin{array}{l}\text { Desa } \\
\text { Komitmen Organisasi }\end{array}$ & 0.474 & 0.294 & $\mathbf{0 . 7 8 5}$ & & & \\
$\begin{array}{l}\text { Pengawasan BPD } \\
\text { Pengelolaan Keuangan }\end{array}$ & 0.567 & 0.430 & 0.640 & $\mathbf{0 . 7 5 5}$ & & \\
\hline
\end{tabular}

Sumber: Data diolah dengan SmartPLS 3.2.8, 2019

\section{Uji Composite Reliability}

Suatu konstruk dikatakan reliabel apabila nilai composite reliability lebih besar dari 0,7. Adapun nilai composite reliability dalam penelitian ini disajikan dalam tabel berikut :

Tabel IV.20

Nilai Composite Reliability

\begin{tabular}{lccc}
\hline \multicolumn{1}{c}{ Variabel } & $\begin{array}{c}\text { Composite } \\
\text { Reliability }\end{array}$ & Nilai Cut-Off & Keterangan \\
\hline Kapabilitas Aparatur Desa & 0.878 & 0.7 & Reliabel \\
Komitmen Organisasi & 0.813 & 0.7 & Reliabel \\
Implementasi SISKEUDES & 0.865 & 0.7 & Reliabel \\
Pengawasan BPD & 0.868 & 0.7 & Reliabel \\
Pengelolaan Keuangan Desa & 0.914 & 0.7 & Reliabel \\
Akuntabilitas & 0.909 & 0.7 & Reliabel \\
\hline
\end{tabular}

Sumber: Data diolah dengan SmartPLS 3.2.8, 2019

\section{Evaluasi Model Struktural / Inner Model Coefficient of Determination ( $R^{2}$ Value)}

Nilai koefisien determinasi digunakan untuk memprediksi seberapa besar kontribusi pengaruh variabel eksogen terhadap variabel endogen. Nilai Coefficient of Determination $\left(R^{2}\right.$ Value) penelitian ini disajikan pada tabel berikut:

Tabel IV.21

Nilai $R^{2}$ Value

\begin{tabular}{lccc}
\hline \multicolumn{1}{c}{ Variabel } & $R^{2}$ Value & $R^{2}$ Adjusted & Kategori \\
\hline Akuntabilitas & 0.602 & 0.592 & Moderate \\
Pengelolaan Keuangan Desa & 0.746 & 0.716 & Substansial
\end{tabular}

Sumber: Data diolah dengan SmartPLS 3.2.8, 2019 


\section{Effect Size $\left(f^{2}\right)$}

Nilai Effect Size $\left(f^{2}\right)$ digunakan untuk melihat kebaikan model dan kontribusi masingmasing variabel eksogen terhadap variabel endogen (Ardiansyah, 2017). Nilai Effect Size ( $f$ $\left.{ }^{2}\right)$ dalam penelitian ini disajikan pada tabel berikut :

Tabel IV.22

Nilai Effect Size $\left(f^{2}\right)$

\begin{tabular}{lccc}
\hline \multicolumn{1}{c}{ Variabel } & $\begin{array}{c}\text { Pengeloaan } \\
\text { Keuangan Desa }\end{array}$ & Akuntabilitas & $\begin{array}{c}\text { Kategori } \\
\text { Kontribusi }\end{array}$ \\
\hline Kapabilitas Aparatur Desa & 0.017 & & Kecil \\
Komitmen Organisasi & 0.291 & & Sedang \\
Implementasi SISKEUDES & 0.184 & & Sedang \\
Pengawasan BPD & 0.318 & & Sedang \\
Pengelolaan Keuangan Desa & & 1.514 & Besar \\
\hline
\end{tabular}

Sumber: Data diolah dengan SmartPLS 3.2.8, 2019

\section{Predictive Relevance ( $Q^{2}$ Value)}

Apabila nilai $Q^{2}$ Value $>0$, maka model pengukuran memenuhi kriteria predictive relevance dan begitupun sebaliknya. Adapun nilai predictive relevance penelitian ini diperoleh dari prosedur blindfolding disajikan dalam tabel berikut :

Tabel IV.23

Nilai Cross-Validate Communality Analisis Blindfolding

\begin{tabular}{lccc}
\hline \multicolumn{1}{c}{ Variabel } & SSO & SSE & $\begin{array}{c}\mathrm{Q}^{2}(=1- \\
\text { SSE/SSO })\end{array}$ \\
\hline Kapabilitas Aparatur Desa & 156.000 & 102.966 & 0.340 \\
Komitmen Organisasi & 195.000 & 128.651 & 0.340 \\
Implementasi SISKEUDES & 156.000 & 121.939 & 0.218 \\
$\begin{array}{l}\text { Pengawasan BPD } \\
\text { Pengelolaan Keuangan }\end{array}$ & 156.000 & 78.367 & 0.498 \\
$\begin{array}{l}\text { Desa } \\
\text { Akuntabilitas }\end{array}$ & 234.000 & 128.745 & 0.450 \\
\hline
\end{tabular}

Sumber: Data diolah dengan SmartPLS 3.2.8, 2019

\section{Pengujian Hipotesis}

\section{Uji Signifikansi Parameter Individual (Uji Statistik t)}

Uji hipotesis dalam penelitian ini menggunakan model pengujian 1 arah (one tailed) dengan nilai tabel sebesar 1.66. Hasil uji hipotesis disajikan dalam tabel berikut :

Tabel IV.24 Nilai Path Coefficient Analisis Bootsrapping

\begin{tabular}{ccccccc}
\hline Uraian & Korelasi & $\begin{array}{c}\text { Original } \\
\text { Sampel } \\
\text { (Arah } \\
\text { Hubungan) }\end{array}$ & $\boldsymbol{t}_{\text {statistik }}$ & $\mathbf{t}_{\text {tabel }}$ & $\begin{array}{c}\boldsymbol{P} \\
\text { Value } \\
\text { (sig) }\end{array}$ & Keputusan \\
\hline Hipotesis 1 & KA > PK & 0.085 & 0.606 & 1.66 & 0.272 & Non Sig \\
Hipotesis 2 & KO > PK & 0.381 & 3.943 & 1.66 & 0.000 & Signifikan \\
Hipotesis 3 & IS > PK & 0.263 & 2.885 & 1.66 & 0.002 & Signifikan \\
Hipotesis 4 & PB > PK & 0.359 & 3.094 & 1.66 & 0.001 & Signifikan \\
Hipotesis 5 & PK > AB & 0.776 & 11.350 & 1.66 & 0.000 & Signifikan \\
\hline
\end{tabular}

Sumber: Data diolah dengan SmartPLS 3.2.8, 2019 


\section{Uji Signifikansi Simultan (Uji Statistik F)}

Nilai $F_{\text {hitung }}$ dapat diketahui dengan melakukan perhitungan manual menggunakan rumus dibawah ini :

$$
F_{\text {hitung }}=\frac{R^{2} / k}{1-R^{2}(n-k-1)}
$$

Dimana :

$\mathrm{R}^{2}=$ Koefisien Determinasi

$\mathrm{k}=$ Jumlah variabel independen

$\mathrm{n}=$ Ukuran Sampel

$$
\begin{aligned}
F_{\text {hitung }}= & \frac{0.746 / 4}{1-0.746 /(50-4-1)} \\
F_{\text {hitung }} & =\frac{0.1865}{0.006} \\
& =31.083
\end{aligned}
$$

Nilai $F_{\text {tabel }}$ pada signifikansi $5 \%$ dengan df1 $=3$ dan df2 (50-4-1) $=45$ adalah sebesar 2.61. Hal ini menunjukkan nilai $F_{\text {hitung }}>F_{\text {tabel }}$ yaitu $31.083>2.61$ sehingga dapat disimpulkan bahwa variabel kapabilitas Aparatur Desa, komitmen organisasi, implementasi SISKEUDES dan pengawasan BPD secara bersama-sama (simultan) berpengaruh terhadap variabel pengelolaan keuangan desa.

\section{Indirect Effect}

Dalam penelitian ini, analisis Indirect Effect bertujuan untuk mengetahui pengaruh tidak langsung kapabilitas Aparatur Desa, komitmen organisasi, implementasi SISKEUDES dan pengawasan BPD terhadap variabel akuntabilitas. Nilai indirect effect disajikan dalam tabel berikut :

\section{Tabel IV.27 Nilai Indirect Effect}

\begin{tabular}{cccccc}
\hline Korelasi & $\begin{array}{c}\text { Original } \\
\text { Sampel }\end{array}$ & $\mathbf{t}_{\text {statistik }}$ & $\mathbf{t}_{\text {tabel }}$ & Keterangan & $\begin{array}{c}\boldsymbol{P} \text { Value } \\
\text { (sig) }\end{array}$ \\
\hline $\mathrm{KA}->\mathrm{AB}$ & 0.066 & 0.581 & 1.66 & Tidak Didukung & 0.281 \\
$\mathrm{KO}->\mathrm{AB}$ & 0.295 & 3.423 & 1.66 & Didukung & 0.000 \\
$\mathrm{IS}->\mathrm{AB}$ & 0.204 & 2.432 & 1.66 & Didukung & 0.008 \\
$\mathrm{~PB}->\mathrm{AB}$ & 0.278 & 2.549 & 1.66 & Didukung & 0.006 \\
\hline
\end{tabular}

Sumber: data diolah dengan SmartPLS 3.2.8, 2019

\section{SIMPULAN DAN SARAN}

\section{Simpulan}

Berdasarkan hasil penelitian dan pembahasan yang telah diuraikan, maka peneliti menarik kesimpulan sebagai berikut : Kapabilitas Aparatur Desa berpengaruh positif tidak signifikan terhadap pengelolaan keuangan desa di Desa Banyu Asin Kecamatan Riau Silip Kabupaten Bangka yang berarti bahwa semakin tinggi kapabilitas yang dimiliki Aparatur Desa 
maka kinerja yang dihasilkan akan semakin baik. Komitmen organisasi berpengaruh positif signifikan terhadap pengelolaan keuangan desa di Desa Banyu Asin yang berarti bahwa semakin tinggi komitmen organisasi maka semakin tinggi pula motivasi agar pengelolaan keuangan dapat terselesaikan tepat waktu. Implementasi SISKEUDES berpengaruh positif signifikan terhadap pengelolaan keuangan desa di Desa Banyu Asin yang berarti bahwa semakin optimal implementasi SISKEUDES maka pengelolaan keuangan di Desa Banyu Asin akan semakin baik. Pengawasan BPD berpengaruh positif signifikan terhadap pengelolaan keuangan desa di Desa Banyu Asin yang berarti bahwa semakin tinggi tingkat pengawasan BPD maka pengelolaan keuangan di Desa Banyu Asin akan semakin baik. Pengelolaan keuangan desa berpengaruh positif signifikan terhadap akuntabilitas yang berarti bahwa semakin baik pe ngelolaan keuangan desa maka semakin baik pula tingkat akuntabilitas.

\section{Saran}

Saran yang dapat diberikan untuk penelitian selanjutnya adalah sebagai berikut : Penelitian selanjutnya diharapkan memperluas lingkup penelitian dengan menambah objek penelitian dan tidak hanya fokus pada satu objek penelitian saja, misalnya pada Desa-Desa se-Kecamatan atau se-Kabupaten. Selain itu penelitian yang mengangkat konsep "Determinan Pengelolaan Keuangan" juga dapat dilakukan pada sektor swasta untuk memperluas lingkup penelitian sehingga dapat mewakili (generalisasi) wilayah lain dalam issue yang sama. Menambah jumlah variabel independen/eksogen agar dapat menguatkan konstruk yang dibangun khususnya yang berkenaan dengan pengelolaan keuangan desa dan akuntabilitas.Menambah jumlah responden khususnya pihak eksternal seperti masyarakat untuk menguji tingkat akuntabilitas pengelolaan keuangan desa. Hal ini dilakukan untuk memberikan informasi yang lebih akurat terkait kondisi rill yang terjadi di lapangan terkait pengelolaan keuangan desa.

\section{REFERENSI}

Amalya, Tuti. Akram dan Pituringsih, E. (2017). “Determinant of Vilage Financial Management and Its Implication toward Accountablity (Study on Village Governance in West Lombok Regency)". International Journal of Research in Advent Technology. Universitas Mataram. Vol. 5, No. 12.

Asrori. (2014). Kapasitas Perangkat Desa Dalam Penyelenggaraan Pemerintahan Desa di Kabupaten Kudus. Jurnal Bina Praja. Vol. 6, No.2.

Erryana, Vinda dan Hendri Setyawan. (2016). Determinan Akuntabilitas Pelaporan Keuangan Pemerintah Daerah (Studi Empiris Pada Pemerintah Daerah se- Jawa Tengah). Jurnal Akuntansi Indonesia. Vol. 5, No.1.

Fahmi, Irham. (2013). Perilaku Organisasi : Teori Aplikasi dan Kasus. Bandung; Alfabeta.

Ghozali, Imam dan Karlina A Kusumadewi. (2016). Model Persamaan Struktural: Partial Least Square Path Modelling (PLS-PM), Generalized Structure Component Analysis (GSCA), Regularized Generalized Canonical Correlation Analysis (RGCCA). Semarang: Yoga Pratama.

Islami, Ulima. (2016). Kapasitas Aparatur Desa Dalam Tertib Administasi Desa (Studi Kasus di Desa Tiuh Tohou, Kecamatan Menggala). Fakultas IImu Sosial dan IImu Politik Universitas Lampung. Lampung. Tidak Dipublikasikan. 
Juardi S S, Muhammad. Mustakim, Muklis. Reski A, Putri. (2018). Evaluasi Penggunaan Aplikasi SISKEUDES Dalam Upaya Peningkatan Akuntabilitas Pengelolaan Keuangan Desa (studi kasus: Desa Jenetallasa, Kecamatan Pallangga, Kabupaten Gowa). Jurnal IImiah Akuntansi Peradaban. Universitas Islam Negeri Alauddin Makassar. Makassar. Vol. IV, No. 1

Kemenkeu RI. (2016). Kebijakan Pengalokasian dan Penyaluran Dana Desa Tahun 2017. Makalah disajikan dalam Seminar Lokakarya Penyusunan Rancangan Peraturan Kepala Daerah Mengenai Tata Cara Perhitungan Pembagian dan Penetapan Rincian Dana Desa TA 2017. Redtop Hotel and Convention Center. 21-24 November 2016.

Munti, Finta dan Hery Fahlevi. (2017). Determinan Kinerja Pengelolaan Keuangan Desa (Studi Pada Kecamatan Gandapura, Kabupaten Bireuen Aceh. Jurnal Akuntansi dan Investasi. Universitas Syiah Kuala. Aceh. Vol. 18, No. 2.

Nafidah, Nasehatun Lita dan Nur Anis. (2017). Akuntabilitas Pengelolaan Keuangan Desa di Kabupaten Jombang. Jurnal IImu Akuntansi. STIE PGRI Dewantara Jombang. Jombang. Vol. 10, No. 2.

Peraturan Menteri Dalam Negeri Republik Indonesia Nomor 113 Tahun 2014 Tentang Pedoman Pengelolaan Keuangan Desa.

Pramitadari, Amrani. (2016). Pengaruh Komitmen Organisasi,Sistem Administrasi dan Sumber Daya Manusia Terhadap Penyusunan Anggaran Berbasis Kinerja Pada Pemerintah Daerah Kabupaten Bangka Barat. Fakultas EkonomiUniversitas Bangka Belitung. Bangka Belitung. Tidak Dipublikasikan.

Rochmansjah, Heru dan Chabib Soleh. (2015). Pengelolaan Keuangan Desa. Bandung: Fokusmedia.

Sugiyono. (2018). Metode Penelitian: Kuantitatif, Kualitatif, dan R\&D. Bandung: Alfbeta. Undang-Undang Nomor 6 Tahun 2014 Tentang Desa Undang-Undang Nomor 17 Tahun 2003 Tentang Keuangan Negara 